\title{
Una aproximación a la formación de la propiedad urbana eclesiástica en la Sevilla bajomedieval
}

\author{
An Approach to the Formation of Ecclesiastical \\ Urban Property in Seville in the Late Middle Ages
}

\author{
Antonio Collantes de Terán Sánchez \\ Universidad de Sevilla. Sevilla, España \\ collante@us.es \\ (D) https://orcid.org/0000-0002-5111-7415
}

\begin{abstract}
Resumen: Este trabajo analiza las fórmulas predominantes para la formación de la propiedad inmobiliaria eclesiástica en Sevilla entre los siglos XIII y XV, a partir de los datos de instituciones, como la Catedral, la colegial del Salvador, conventos y hospitales. En la citada formación tuvieron un papel importante las donaciones, pero en algunos casos predominaron las compras o las transmisiones hereditarias. En el caso de las donaciones, se analiza la procedencia social de los donantes.
\end{abstract}

Palabras claves: Propiedad eclesiástica, Sevilla, siglos XIII-XV

\begin{abstract}
This paper analyses the main formula to build the ecclesiastical real estate in Seville between the 13th and the 15th centuries. This research lies on documents from some institutions as the Cathedral of Seville, the Salvador collegiate church and some convents and hospitals of the city. The donations had an important role in the construction of the properties mentioned before, but, in some cases, purchasing and hereditary transmissions were predominant. Regarding the donations, this paper analysis too where the social donors were from.
\end{abstract}

Keywords: Ecclesiastical Real Estate, Seville, 13th-15th centuries

La iniciativa de los cluniacenses en el siglo $x$ de celebrar misas por sus benefactores ${ }^{1}$ se podría considerar el punto de partida de una práctica que favoreció la creación y desarrollo del patrimonio de numerosas instituciones eclesiásticas. A ello vino a sumarse en siglos

\footnotetext{
1 Cf. Andrè Vauchez, La espiritualidad del Occidente medieval, Madrid, Cátedra, $1985,38,39$.
} 
posteriores un incremento de la preocupación de los fieles por su salvación o, mejor dicho, por el tiempo que habrían de pasar en el purgatorio para la remisión de sus pecados; tiempo que se reduciría mediante la celebración de sufragios por su alma, de ahí la importancia de dejarlos prescritos en los testamentos. Paralelamente, nuevas corrientes de espiritualidad llevaron a muchos fieles a promover la conmemoración de diversas fiestas litúrgicas y a la creación de cofradías, así como a ejercer la virtud de la caridad mediante la fundación de hospitales.

Para el sostenimiento económico de dichas prácticas había que disponer los recursos necesarios, entre ellos, y por lo que afecta a este trabajo, la adscripción o donación de bienes inmuebles, con cuyas rentas garantizarlas a lo largo del tiempo. Inicialmente, quienes estaban en condiciones de efectuar estos desembolsos eran los reyes, los nobles y los grandes funcionarios y altos dignatarios eclesiásticos, por lo que las instituciones beneficiadas lo que recibieron fueron fundamentalmente tierras, que es lo que caracterizó a los patrimonios de los monasterios altomedievales. A partir de los siglos centrales de la Edad Media, esas nuevas corrientes de religiosidad vinculadas al crecimiento de la actividad económica y al desarrollo urbano hizo que las citadas prácticas, hasta entonces reducidas a ese sector minoritario de la sociedad, adquiriesen una rápida expansión al participar de ellas los grupos emergentes de las sociedades urbanas. Las grandes beneficiadas de dicha evolución fueron sobre todo las catedrales, las órdenes mendicantes y otras coetáneas que se suelen asimilar a ellas (agustinos, mercedarios, trinitarios, etc.), en especial las ramas femeninas.

Cuando Sevilla se incorporó a la Corona de Castilla en 1248, ya había tenido lugar el citado cambio de protagonismo de los distintos sectores sociales en la conformación de los patrimonios eclesiásticos. Es verdad que inicialmente hay una presencia regia, pero obedece a otra motivación: la de ocupar y poblar un territorio recién conquistado; sin embargo, a partir de dicho momento inicial, esa presencia será poco significativa. Por lo que se refiere a la nobleza, compartirá su papel con los grupos sociales emergentes integrados por oficiales públicos, alta clerecía, mercaderes, financieros e incluso artesanos. ${ }^{2}$ No

2 Juan de Montemolín, $v^{0}$ de San Martín, que, según su testamento de 1467, se dedicaba al negocio del carbón, poseía una capilla en la parroquia de San Isidoro y creó una capellanía, para la que designó como patrono a un hermano (Archivo Parroquial de S. Isidoro, Escrituras, caja 10-21). Las consideraciones de Juan 
en balde eran los sectores más numerosos en la sociedad sevillana. Según el sondeo de S. Pérez, la gran mayoría de los miembros de las cofradías a finales del siglo XV e inicios del XVI pertenecían al sector artesanal y al de los servicios. ${ }^{3}$ Se trataba de colectivos imbuidos de una religiosidad popular y con unas connotaciones sociológicas que incidían en sus decisiones a la hora de expresar esa religiosidad o de buscar las ayudas espirituales en unas o en otras instituciones y, consecuentemente, canalizar hacia ellas las donaciones de inmuebles, con cuyas rentas garantizar el cumplimiento de sus memorias, servicios religiosos, etc. Al margen de esta finalidad, la otra vía de crecimiento del citado patrimonio fue el papel de los monasterios femeninos como espacios de acogida y/o aislamiento.

Dicho cambio implicó que las propiedades urbanas adquiriesen un creciente protagonismo, ya fuesen casas o distintos tipos de instalaciones de transformación y de comercio. Sobre todo, porque para la mayoría de los donantes eran los únicos bienes raíces de que disponían. Al tiempo, la propiedad acotaba el nivel social de quienes estaban en condiciones de expresar su religiosidad por este medio. Todo ello desembocó en que en los siglos finales de la Edad Media una parte considerable del patrimonio inmobiliario urbano estuviese en manos de las distintas instituciones vinculadas a la Iglesia, con cifras que podían llegar o superar los 2.000 inmuebles, y que dicha dinámica continuase en los siglos posteriores. ${ }^{4}$

Como refleja la ya numerosa bibliografía que ha tratado esta cuestión, los mecanismos dominantes fueron las donaciones —en

Cartaya sobre estas prácticas, aunque basadas en documentación del siglo XVI, son válidas al menos para la centuria precedente (Mayorazgo. Riqueza, nobleza y posteridad en la Sevilla del siglo XVI, Sevilla, Universidad, 2018, 257 y ss.).

3 Cf. Silvia Ma. Pérez González, Los laicos en la Sevilla bajomedieval. Sus devociones y cofradias, Huelva, Universidad, 2005, 143, 144.

4 Para una visión de conjunto de la evolución de la propiedad y del mercado urbano sevillano en los siglos medievales y modernos en la que insertar este análisis, cf. Antonio Collantes de Terán Sánchez,"Propiedad y mercado inmobiliario en la Edad Media: Sevilla, siglo XIII-XVI", Hispania XLVIII/169 (1988) 493-527; Antonio Collantes de Terán SÁNChez, "El modelo meridional: Sevilla", en Mercado inmobiliario y paisajes urbanos en el Occidente Europeo (siglos XI-XV). XXXIII Semana de Estudios Medievales de Estella, Pamplona, Institución Príncipe de Viana, 2007, 591-629. Antonio Luis López Martínez, La economía de las órdenes religiosas en el Antiguo Régimen. Sus propiedades y rentas en el Reino de Sevilla, Sevilla, Diputación Provincial, 1992. 
sus distintas variantes de inter vivos, testamentarias o en concepto de dote-, las herencias y las compraventas. Ahora bien, en lo que ya no se ha profundizado tanto es en aquilatar cómo cada uno de estos procedimientos pudo actuar en cada una de las instituciones o, dicho de otra manera, la importancia relativa de dichos mecanismos en la conformación de sus patrimonios, así como en identificar la procedencia social de sus protagonistas. Es este enfoque el que pretendo desarrollar en el presente trabajo, a partir de una serie de instituciones eclesiásticas que poseen fondos suficientes para poder efectuar esta aproximación, teniendo como horizonte temporal el final de la Edad Media.

Ante todo, hay que tener en cuenta la pluralidad y diversidad de dichas instituciones, tanto en sí mismas consideradas como en sus relaciones con la sociedad. No es lo mismo un poderoso cabildo catedral que una parroquia; una comunidad conventual que una cofradía y/o fundación hospitalaria, ya que estas, al ser entendidas como una manifestación de la caridad cristiana, quedaban bajo la tutela de la jerarquía. ${ }^{5}$ Por otro lado, incluso instituciones de la misma naturaleza, por ejemplo, comunidades conventuales, adoptaron mecanismos distintos, o pusieron más énfasis en unos que en otros, en la formación de su patrimonio. De ahí, la diversidad de situaciones y la conveniencia de analizarlas. ${ }^{6}$

Las fuentes disponibles son deudoras de los avatares de las instituciones que las generaron. Mientras que la Catedral, algunos conventos y hospitales han conservado una parte importante de sus fondos documentales, no ha ocurrido lo mismo con las parroquias ${ }^{7}$ y la mayor parte de los hospitales y/o cofradías. Aparte de esto, hay algo que afecta a todos ellos y es la pérdida de una parte considerable

5 Sobre este aspecto referido a las órdenes mendicantes, cf. José Mª MiURA, Frailes, monjas y conventos. Las órdenes mendicantes y la sociedad sevillana bajomedieval, Sevilla, Diputación Provincial, 1998; para las cofradías y hospitales, Pérez GonzÁlez, Los laicos, 115-274.

6 Ya hace años llevé a cabo una aproximación similar por lo que se refiere a las propiedades rurales de dichas órdenes (Antonio ColLANTES DE TERÁn, "Génesis de la gran propiedad en la Baja Edad Media, la propiedad eclesiástica sevillana", en Gonzalo Anes Álvarez y otros, La economía agraria en la Historia de España. Propiedad, explotación, comercialización rentas, Madrid, Alfaguara, Fundación Juan March, 1979, 133-140).

7 Las pérdidas experimentadas por esta documentación parroquial son tan considerables, que impide su estudio. De ahí, que queden fuera de este análisis. 
de la documentación más antigua, lo que es fundamental dado el enfoque del presente trabajo. Me refiero a las cartas de donación, compraventa, trueque, etc., que son las que permiten conocer al detalle la evolución y los protagonistas. Estas pérdidas pueden ser paliadas con la información aportada por los libros de protocolos que se confeccionaron en estas instituciones a partir del siglo $\mathrm{XVI}^{8} \mathrm{y}$, por otros con contenido más o menos similar pero cuya finalidad era distinta y condicionaba dicho contenido, como el Libro Blanco de la Catedral. ${ }^{9}$ Ahora bien, los datos que aportan son incompletos, porque en ellos figuran los inmuebles que eran propiedad o generaban rentas en el momento de su confección; por tanto, no aparecerán todos aquellos de los que se fueron desprendiendo por cualquier motivo a lo largo de los siglos. ${ }^{10}$ Además, dado lo tardío de la confección se habría perdido parte de la documentación original, por lo que no se pudo precisar ni el cómo, ni el cuándo, ni el quién. ${ }^{11}$ Otra limitación es que, en ocasiones, falta precisión en los datos a la hora de enumerar los inmuebles, con expresiones como "unas casas", "una casa y unas tiendas", etc. De todas formas, teniendo en cuenta todas estas limitaciones, creo que lo conservado es suficiente para intentar evaluar las peculiaridades de cada institución o instituciones en la conformación de sus respectivos patrimonios inmobiliarios.

8 Sobre los libros protocolos de los hospitales sevillanos, cf. Pablo Alberto MestRE Navas, Los libros protocolos de los bienes de los hospitales sevillanos. La administración de propiedades en el Antiguo Régimen, Sevilla, Diputación Provincial, 2017.

9 Según Diego Belmonte FernándeZ, solo se registraron aquellas dotaciones vinculadas a sepulturas, no las restantes (Organizar, administrar, recordar. El Libro Blanco y el Libro de Dotaciones de la Catedral de Sevilla, Sevilla, Universidad de Sevilla, 2019, 39). Aparte de la edición en papel de esta obra, se puede consultar on line en el formato tesis (<https://idus.us.es/handle/11441/44471> [consultado 25 septiembre 2021]), que incluye en Apéndice la trascripción del citado Libro Blanco. Por tanto, en adelante, las citas de datos procedentes del Libro remiten a las páginas de la edición digital.

10 De ahí que se conserven documentos originales de donaciones o compras, que, sin embargo, no aparecen en los Libros de Protocolos o en el Libro Blanco (cf. Belmonte, Organizar, 38, 39). En el caso de Sta. Clara, de las tres casas donadas en 1364 por Marina Sánchez, solo figura una en el Libro becerro (cf. Gloria CENTENO Carnero, Real Monasterio de Santa Clara de Sevilla. Colección diplomática, 12641569, 2 vols., Sevilla, Ayuntamiento de Sevilla, 2017, 128).

11 En algunos Libros de protocolo, cuando se da esta circunstancia, se resuelve mediante la expresión "posesión antigua". A veces, los vacíos se pueden cubrir con los contratos originales conservados. 
Como no podía ser de otro modo, el punto de partida debería ser la más poderosa, la Catedral. Hasta que no se culmine el vaciado completo de la riquísima documentación conservada en la sección Ix de su Archivo (Fondo Histórico General) no se podrá ofrecer una imagen más o menos ajustada del proceso de formación del enorme patrimonio inmobiliario urbano acumulado. Actualmente, el mejor medio para aproximarse lo ofrece el mencionado Libro Blanco, confeccionado en $1411 .^{12}$ Dentro de la tipología de los códices diplomáticos, Belmonte lo define como un tipo de libro nuevo que recoge, organiza y actualiza la memoria funeraria y patrimonial de la Catedral de Sevilla, investido de la legitimidad social que le proporcionaba la propia institución. ${ }^{13}$ La mayor parte de su contenido está relacionado con la dotación de las capellanías, por lo que se centra en la identificación de los donantes, los bienes donados y las correspondientes obligaciones de la institución hacia ellos. ${ }^{14}$ Además, incluye una relación de inmuebles de distinta naturaleza (mezquitas, tiendas y edificios con funciones industriales o de transformación), ${ }^{15}$ aunque sin ningún tipo de información que permita conocer su procedencia y cómo llegaron a ser propiedad del Cabildo, con excepción de las mezquitas. ${ }^{16}$

Según los datos del Libro Blanco, en el momento de su confección la Catedral era propietaria de 376 inmuebles, aunque debido a las características de la fuente, el número de los que permiten el análisis es de 333, que fueron entregados por 165 donantes identificados. ${ }^{17}$ Dejando a un lado al monarca, Alfonso x, que donó 55,

12 De este códice se han hecho dos ediciones. La primera, por Javier Pérez-EMBID WAMBA, que utiliza la copia conservada en la Real Academia de la Historia (Culto funerario y registro necrológico de la Catedral de Sevilla [siglos XIII-XV], Madrid, Dykinson, 2015); la segunda, por Diego Belmonte en la obra ya mencionada sobre el códice de la Catedral, que es la que he utilizado para este trabajo.

13 Cf. Belmonte, Organizar, 147.

14 Cf. Belmonte, Organizar, 377-499. A pesar de su gran utilidad para el análisis que aquí se pretende, tiene dos limitaciones: la ausencia casi generalizada de cronología de las donaciones, que a veces se puede conocer cuando se conservan los contratos originales, y la condición o actividad de muchos de los donantes.

15 Cf. Belmonte, Organizar, 503-505.

16 El documento de concesión en Manuel GonZÁLEZ Jiménez (ed.), Diplomatario andaluz de Alfonso x, Sevilla, Fundación El Monte, 1991, 7.

17 Aparte de estos, hay siete inmuebles de los que no se indica el donante, y una relación independiente de otros 36, que figuran bajo el epígrafe "Mezquitas e 
entre ellos 50 mezquitas, el protagonismo correspondió a los propios clérigos de la Catedral, que con 80 miembros, incluidos arzobispos y obispos, suponen el 38,5\%, aunque probablemente superasen dichas cifras, pues no hay información sobre la condición o actividad de un elevado número de donantes. Le siguen a gran distancia los nobles y la aristocracia, con 41 donantes (18,7 \%). Varios de ellos pertenecían al entorno real, como Juan Mate de Luna, que figura como camarero de Alfonso x; Fernán Pérez Maimón, consejero y chanciller de Sancho Iv; Alvar Pérez de Guzmán, señor de Olvera, almirante y alguacil mayor de Sevilla. También alcaldes mayores de Sevilla o sus mujeres o viudas, como las de Juan Fernández de Mendoza y Fernán Martínez; otros nobles y miembros del Ayuntamiento, como el señor de Los Molares, Lope Gutiérrez de Toledo, el veinticuatro Guillén Alfonso deVillafranca, o Guillén de las Casas. ${ }^{18}$ Hay varios calificados de caballeros. En función de los datos disponibles, la mayor parte de ellos pertenecerían al grupo de quienes participaron en la conquista y permanecieron en la ciudad. ${ }^{19}$ Como se observará, la nómina de miembros de la élite es más bien reducida para una catedral como la de Sevilla, pero no debe extrañar, ya que donde realmente se hizo presente este grupo social fue en las donaciones de bienes rurales. ${ }^{20}$ Las mujeres suman 35 (16,8 \%), de las que al menos once figuran como viudas. El resto de los donantes laicos no llega a la treintena, entre los que destacan el notario mayor de Andalucía, García Martínez, y el escribano real y mayor del concejo, Nicolás Pérez de Villafranca, ${ }^{21}$ así como nueve comerciantes, mientras que los artesanos quedan reducidos a dos.

Excluyendo las regias, el promedio de donaciones es bastante modesto, 1,6 inmuebles por donante eclesiástico y hombres laicos, mientras que en las mujeres baja al 1,5. De este panorama se destaca un reducido número de miembros de la aristocracia y de eclesiásticos

bannos e atahonas de la çibdad <e > de fuera que pertenesçen al arçobispo e al cabildo" (pp. 503-505), de los que, salvo las mezquitas y alguna tienda, del resto no se indica su origen. Probablemente, cuando esté completada la catalogación de la sección ix se puedan identificar.

18 Cf. Belmonte, Organizar, 379, 388, 407, 434, 435, 490.

19 Cf. Isabel Montes Romero CAMACHO, Propiedad y explotación de la tierra en la Sevilla de la Baja Edad Media, Sevilla, FOCUS, 1988, 36, 37. Probablemente, muchos de los donantes que figuran sin identificar pertenecerían al citado colectivo.

20 Cf. Montes Romero Camacho, Propiedad y explotación, 35-37.

21 Cf. Belmonte, Organizar, 450, 492. 
vinculados a la Catedral, con aportaciones que llegaron hasta los seis y siete inmuebles. Entre los miembros del Cabildo los máximos donantes fueron nueve, con cinco inmuebles cada uno. Lo llamativo de este grupo no es tanto la cifra de inmuebles como su tipología. La gran mayoría fueron tiendas y otros edificios dedicados a actividades económicas: el ya mencionado Nicolás Pérez de Villafranca entregó siete tiendas en la Ollería; Marina Lorenzo, viuda del alcalde mayor Fernán Martínez, cuatro en la calle de los Francos y un corral horno; Fernán Pérez Maimón, varias tiendas en las Gradas de la Catedral, entre ellas una de cambiador, un mesón, cerca de la Alhóndiga y unos baños en la collación de Sta. Catalina. ${ }^{22}$ Entre los eclesiásticos, el arzobispo Fernán Gutiérrez Tello donó cuatro tiendas y un almacén; ${ }^{23}$ el canónigo Andrés Díaz, cuatro tiendas y una casa; un clérigo de Las Cabezas de San Juan, Benito Fernández, tres tiendas, dos casas tiendas y unas casas; dos arcedianos, Fernán Martínez de Mansilla y Juan de Pomes, cuatro casas cada uno y una tienda o un mesón. ${ }^{24}$

Hasta aquí, la instantánea que ofrece el Libro Blanco. A partir de aquí, solo parcialmente es posible conocer la evolución del patrimonio. En el mismo códice se fueron asentando posteriores donaciones, hasta alcanzar 95 nuevos inmuebles a fines del siglo xv. Sin embargo, al igual que en la etapa anterior, no se recogieron todas. ${ }^{25}$ Teniendo esto en cuenta, lo primero que se observa es una considerable reducción. Si hasta 1411 la frecuencia había sido de 2,4 inmuebles por año; a partir de la citada fecha descendió a 1,4. Otro cambio que destacar es que los laicos prácticamente desaparecieron. Solo aparecen cinco, de los cuales, cuatro son mujeres, frente a 33 clérigos vinculados a la Catedral. Las más importantes fueron del racionero Pedro Martínez de la Caridad y de doña Guiomar Manuel. El primero donó ocho casas y la segunda, cinco tiendas en la Alcaicería, unas casas tienda

22 Cf. Belmonte, Organizar, 407, 467, 492.

23 Su hermana donó un mesón, un horno y unas casas (cf. Belmonte, Organizar, 390, 440).

24 Cf. Belmonte, Organizar, 391-393, 489.

25 Creo que es factible comparar estos datos con los anteriores a 1411. Según la opinión de Belmonte, más arriba mencionada, las donaciones registradas corresponderían a obligaciones derivadas de la concesión de sepulturas y memorias de misas, por lo que las que no tenían dichas vinculaciones no deben aparecer en el Libro Blanco. En consecuencia, las nuevas inscripciones deben seguir respondiendo a dicho criterio. 
y dos casas. ${ }^{26}$ Una posible justificación de este cambio tan radical estaría en el hecho de que en 1433 se inició la construcción del nuevo edificio gótico, por lo que el interés por enterrarse en ella y la dotación de capillas quedarían afectados. ${ }^{27}$

Como síntesis de los dos periodos analizados, entre 1252 y 1500, los clérigos representan prácticamente la mitad de los donantes, y casi todos ellos eran miembros del Cabildo catedralicio y otros servidores, a los que añadir cinco arzobispos. Entre ellos se cuentan 3 deanes, 16 arcedianos, 4 maestrescuelas, 4 chantres, 43 canónigos, 19 racioneros y 6 compañeros. En cuanto a los laicos, aparte de la ya mencionada presencia femenina, de los 28 hombres de los que se dispone de información, la mayoría pertenecían al siglo XIII e inicios del $\mathrm{XIV}^{28}$ y frente a la presencia de grandes nobles y funcionarios, el resto de la sociedad sevillana está poco representada, destacando varias personas ligadas al comercio, que si bien alguna es de la primera hora, otras llegaron ya avanzado el siglo xV, como un mesonero, quizá como símbolo del ascenso de gente nueva que se estaba dando en la sociedad sevillana.

Aunque el conocimiento del patrimonio urbano de la Catedral es imperfecto, de lo visto hasta aquí, queda claro que el mecanismo fundamental de formación fueron las donaciones. Esto no excluye que también se recurriera a las compras, si bien debieron tener un papel muy secundario y, además, en muchos casos también estuvieron relacionadas con las donaciones, en este caso, en metálico, porque las pocas compras que refleja el Libro Blanco se hicieron con mandas en dinero, entregadas para que se invirtiesen en la adquisición de bienes raíces que generasen rentas.

Por lo que se refiere a la Colegiata del Salvador, la segunda iglesia de la ciudad desde un punto de vista jerárquico, y que en sus orígenes había sido la primitiva mezquita mayor musulmana, presenta

26 El racionero donó, además, una casa al Hospital de S. Bernardo o de los Viejos (cf. Belmonte, Organizar, 412-413, 454-458). Sobre doña Guiomar, cf. Rafael SÁNCHEZ SAus, La Sevilla de doña Guiomar Manuel. Un ejemplo medieval de evergesía cívica y cristiana, Sevilla, Fundación Real Maestranza de Caballería de Sevilla, 2015.

27 Esto conecta con la limitación del Libro Blanco acabada de mencionar. Con motivo de dicha construcción, la Fábrica de la Catedral comenzó a recibir un extraordinario número de donaciones, pero estas no figuran en aquel, ya que su destino era diferente. Los 36 inmuebles que figuran en las cuentas de Fábrica de 1420, se convirtieron en 187 en 1499 (ACS, Sec. IV, libro 376).

28 Hay catorce donaciones de las que se desconoce su autor. 
un comportamiento bastante diferente. No solo por lo que se refiere al volumen de su patrimonio, sino también por su tipología y las características de los donantes. Del más del centenar de inmuebles propiedad del Cabildo y de la Fábrica de la Colegiata, 73 pertenecían al Cabildo, de ellos, 22 carecen de datos sobre cómo llegaron a la institución. El libro protocolo capitular recoge 38 donaciones, por 5 trueques y 7 compras, de las cuales, al igual que ocurrió en la Catedral, dos se efectuaron para dotar capellanías. ${ }^{29}$ Según estas cifras, lo lógico es pensar que la mayor parte de los inmuebles de origen desconocido también fuesen donaciones. Por lo que respecta a los conocidos, los donantes fueron 17, siete hombres y diez mujeres, de las cuales cuatro eran viudas. Como es normal, de las mujeres poco más se sabe, dos eran esposas de alcaldes mayores y una era emparedada en el emparedamiento de la propia iglesia. En cuanto a los hombres, destacan dos miembros de la familia Tolosán o Tolosano; Arnao, que era veinticuatro, y Jaime, quienes fueron los mayores donantes, junto con un alguacil de a caballo. Sin embargo, llama la atención que solo aparezca un canónigo de la colegiata, aunque supongo que alguno de los desconocidos también lo fuera. Aparte de estos, únicamente figura un artesano (albardero). En lo que sí existe un paralelismo con el Cabildo Catedral es en el volumen de inmuebles con funcionalidad económica que recibió, ya que hubo una cifra similar de casas y de esos otros inmuebles, con especial relevancia de las tiendas. La mayor parte llegaron por donación de los tres personajes acabados de mencionar: Arnao Tolosán, cuatro casas, dos de ellas bodegas y la cuarta parte de siete tiendas; Jaime Tolosán, cinco tablas de carnicería, y el alguacil Alfonso Martínez de Pontevedra, tres casas y tres tablas de carnicería. ${ }^{30}$

En cierto modo, la importancia de las tiendas tiene sentido aquí. La mayor parte de los inmuebles estaban en la propia collación o parroquia (48), y el entorno de la Colegiata, como heredera de la citada primitiva mezquita mayor, había conservado, tras la conquista castellana, su función de espacio del mercado, por tanto, estaba poblado de tiendas, y el propio edificio rodeado de ellas adosadas a sus

\footnotetext{
29 Cf. Archivo General del Arzobispado de Sevilla (AGAS), Colegial del Salvador, libro 709B. Una relación de los pertenecientes a la Fábrica en 1500 se puede encontrar en un libro de visitas de la citada fecha (libro 743).

30 Cf. AGAS, Colegial del Salvador, libro 709B, protocolos 1, 20, 25.
} 
fachadas. Por tanto, es lógico que muchas acabaran formando parte de su patrimonio.

El de las órdenes religiosas presenta una cierta diversidad, dependiendo de sus estatutos y de las estrategias adoptadas por cada una. En las ordenes mendicantes y las asimiladas, las diferencias se establecieron entre las ramas masculina y femenina. La prohibición, al menos inicial, de que aquellas pudieran tener propiedades y rentas, aunque no siempre se cumplió, sí contribuiría a frenar la creación de patrimonios más o menos notables, algo que no ocurrió con las femeninas, al no estar sometidas a dicha prohibición. Un ejemplo es el convento de San Francisco, fundado poco después de la conquista de la ciudad y uno de los más importantes. A pesar de dicha importancia, en 1500 solo contaba con una veintena de inmuebles, mientras que el femenino de la misma orden, Santa Clara, superaba el centenar. ${ }^{31}$ Por su parte, la Cartuja de Santa María de las Cuevas, a la que no afectaba la citada prohibición, en un siglo acumuló 48 inmuebles.

Volviendo al convento de San Francisco, la relación que figura en el citado Libro Becerro de Sta. Clara no coincide exactamente con los datos de las cartas originales, ni con los procedentes de otras fuentes, como el Libro Blanco de la Catedral. Esto puede deberse, como señalé más arriba, a decisiones relacionadas con la gestión del patrimonio a lo largo de estos siglos; en concreto, que por distintos motivos algunas propiedades acabasen siendo vendidas o trocadas. Las 26 que mencionan dichas fuentes llegaron al convento por donación; $; 2$ de las que diez lo fueron por mujeres. Dada la importancia alcanzada por la comunidad franciscana, muchos donantes pertenecieron a la élite sevillana, como Enrique Enríquez, hijo del infante don Enrique, que le donó varias casas y hornos de ollería, Beatriz Fernández del Marmolejo, viuda del camarero de Juan II, Pedro Fernández, Juan de

31 En dicho año, en cumplimiento de la disposición que ordenaba recuperar el espíritu inicial de la orden, se adscribieron a este las propiedades de San Francisco, y así figuran en el Libro Becerro o de Protocolo (cf. Cennteno Carnero, Real Monasterio de Santa Clara, 42, 43).

32 Es posible que su número fuera mayor, pues no he localizado un documento que relacione todas sus propiedades, y esta cifra procede de fuentes distintas (cf. ACS, IX Fondo Histórico, leg. 95, n 16. Archivo del Monasterio de Santa María de Jesús (AMSMJS), Libro becerro Sta. Clara (LBSC), ff. 98, 153. Cf. Centeno CARnero, El Real Monasterio de Santa Clara, no 86, 111-113, 189, 241, 245, 267, 300. Cf. Belmonte, Organizar, 509, 511). 
Monsalve, el veinticuatro Lorenzo García de Cáceres, la viuda del jurado del Barrio de Francos Juan Márquez.

Las donaciones también definen la formación del patrimonio de la Cartuja de Santa María de las Cuevas, fundada en 1400. A lo largo de la centuria recibió 44 inmuebles sobre un total de 48, los cuatro restantes fueron dos compras, un trueque y una herencia. ${ }^{33}$ En cuanto a la procedencia sociológica de los 25 donantes, se observa una mayor diversidad de lo hasta ahora visto. El grupo más numeroso es el de mujeres (10), de las cuales seis eran viudas y cinco miembros de la aristocracia sevillana. En cuanto a las profesiones, en esta ocasión, el predominio correspondió a los sectores vinculados al artesanado (carpintero, orfebre, tejedor), a los servicios (armador) y al doméstico, como Juan Fernández de los Ríos, criado del alcalde mayor Martín Fernández Cerón, que es el mayor donante, con tres casas y tres tablas de carnicería; seguido de un orfebre, con una casa y tres tiendas en la Alcaicería; un tejedor, con tres casas; y del jurado Juan de Deza, con una casa y dos tablas de carnicería. Además, figuran un canónigo, un cartujo y un bachiller.

Frente a la modestia relativa de estos patrimonios, los de varias órdenes femeninas presentan una imagen totalmente diferente, al tiempo que el mayor volumen de la documentación conservada permite profundizar en los paralelismos y diferencias. De entre todos ellos, destacan dos por su antigüedad e importancia: San Clemente y Santa Clara.

El monasterio cisterciense de San Clemente se fundó en la segunda mitad del siglo xIII con el apoyo de la monarquía, que durante estos siglos lo tuvo bajo su protección, pues no en balde se convirtió en panteón real, al estar enterrada una reina de Castilla y varias infantas. Quizás por ello, numerosas mujeres de las élites sevillanas profesaron en él. ${ }^{34}$ Este apoyo regio no se manifestó a través de la donación de bienes inmuebles, como había sido lo habitual en las centurias precedentes, por lo que el enorme volumen de propiedades que llegó a acumular lo fue gracias a decisiones de particulares.

33 Cf. Archivo Real Academia de la Historia. Libro de Protocolos de la Cartuja de Santa María de las Cuevas, sig. 9/2098. Como reflejo de las estrategias de estas instituciones, frente a esta escasez de compras urbanas, un tercio de las propiedades rurales se adquirieron por este procedimiento.

34 Cf. Mercedes Borrero Fernández, El Real Monasterio de San Clemente. Un monasterio cisterciense en la Sevilla medieval, Sevilla, Ayuntamiento de Sevilla, 1991. 
Uno de los rasgos originales de la política de este monasterio, que, por lo hasta ahora conocido, es el único que la llevó a cabo o, al menos, en las magnitudes que alcanzó, fue la de promocionar la urbanización de los compases y huertas de la periferia mediante su parcelación y cesión a título enfitéutico a particulares para que las edificasen, pagando una renta al monasterio. Dicha política, documentada ya en el primer tercio del siglo XIV, estuvo vigente hasta la segunda mitad del siglo XVI. Como consecuencia de ella, según el Libro de Cuentas de 1495, el primer compás contaba en la citada fecha con 26 casas; el segundo, con 32; y en su periferia (las vueltas de las Lumbreras) había otras 32, lo que hace un total de 90.35

Además, una cantidad similar de inmuebles fueron entregados por particulares a lo largo de las centurias medievales: casi medio centenar en el siglo XIV y algunos menos en el XV. Como señala M. Borrero, las cifras no se pueden ajustar debido a la mencionada falta de datos, pero también, a la dinámica del mercado inmobiliario, que generaba fusiones y fragmentaciones de parcelas.

Otro rasgo distintivo de este monasterio es el mecanismo mediante el cual fue construyendo el patrimonio: las herencias de las propias monjas. ${ }^{36}$ Según los datos aportados por el Libro de Protocolos, de los 82 de los que se poseen datos, 51 (62,2 \%) fueron herencias, mientras que las donaciones supusieron el 25,6 \% (21), y 12,2 \% (10) las compras. Las herencias lo fueron de 29 monjas. La mayoría (19) solo entregó un inmueble. Pero las de algunas fueron excepcionales, como la de María Rodríguez de Rojas, abadesa entre 1324 y 1340, que dejó 12 tiendas ubicadas en la Alcaicería. ${ }^{37}$ Aunque de menor entidad, también fueron importantes las de Inés de Vargas, abadesa entre 1481 y 1491, que dejó cinco casas; y la de Elvira Sánchez, viuda e hija del mercader Francisco Pérez, con cuatro tiendas de paños y una casa. Con tres casas figura otra Elvira Sánchez, hija del alcalde del rey Mateo Pérez. En cuanto a los donantes, fueron once, encabezados por

35 Cf. Borrero Fernández, El Real Monasterio de San Clemente, 107, 109. Archivo del Monasterio San Clemente, Libro de cuentas de 1495.

36 Es el mismo que se empleó en la formación de la propiedad rural (cf. BORRERO FERnÁndez, El Real Monasterio de San Clemente, 96 y ss.).

37 Era hermana del alguacil mayor Ruy Díaz de Rojas. Las había recibido en herencia de su madre, doña Marina Gómez de Sotomayor, monja en las Huelgas de Burgos, a quien se las había donado en 1316 el rey Alfonso XI (cf. BorRero FERnÁNDEZ, El Real Monasterio de San Clemente, 106). 
el rey Fernando Iv, que entregó cinco tiendas de ollería. Otros fueron el arzobispo don Remondo, que efectuó la primera donación al nuevo monasterio (un horno), un canónigo y otro clérigo, un escribano, el veinticuatro Lorenzo García de Cáceres, cuatro mujeres, de las que una era monja de San Clemente y otra del de las Dueñas. ${ }^{38}$ Por lo que se refiere a las compras, que fueron muy pocas (10) para la larga vida del monasterio, la mayoría (8) tuvieron lugar a lo largo del siglo $\mathrm{XV}$, y siempre fueron casas, con la excepción de la última que fue un lagar. No es posible conocer el sentido de dichas compras, pues están dispersas por distintas collaciones, y solo algunas de estas son las de mayor nivel económico. En cuanto a que existiese la intención de adquirirlas para ampliar las colindantes, solo de una se sabe que lindaba con otra del monasterio.

En un nivel similar a este monasterio de San Clemente se encontraba el franciscano de Santa Clara, igualmente fundado en la segunda mitad del siglo XIII con el amparo de la realeza, hasta el punto de instalarse en las casas que habían pertenecido al infante don Fadrique, hermano de Alfonso x. Otro paralelismo lo ofrece el protagonismo de las propias monjas, ${ }^{39}$ pues el mayor volumen de las incorporaciones fue a través de sus herencias (34), a lo que se añade que también fue el grupo más numeroso (9) de los donantes. Aparte de ellas, figuran dos mujeres laicas y solo tres hombres: un mercader, y dos clérigos. Los mayores donantes fueron Pascuala de Talavera, viuda de Ruy de Fortún Pérez, quien entregó dos casas con lagares, una bodega y una huerta; el mercader mallorquín, Arnaldi de Comillas, con tres casas; y la monja Marina González, con otras tres. ${ }^{40}$

Si las herencias y donaciones reproducen comportamientos de otras comunidades, lo original de este monasterio es la importancia que otorgó a las compras, pues alcanzaron las 24 operaciones. ${ }^{41}$ Se concentraron en dos periodos: desde el momento de la fundación hasta el primer tercio del siglo XIV, y en la segunda mitad del siglo

38 Cf. Borrero Fernández, El Real Monasterio de San Clemente, 104.

39 De los 111 inmuebles que figuran en el Libro becerro, 29 no dan datos sobre cómo llegaron al monasterio (AMSMJS, LBSC).

40 Cf. Centeno Carnero, El Real Monasterio de Santa Clara, n 10, 49. AMSMJS, LBSC, f. 66.

41 Dicha importancia es mayor por lo que respecta al patrimonio rural, al menos en número de operaciones, pues doblan al resto de los procedimientos (cf. Collantes de Terán, "Génesis", 135). 
XV. Sobre el sentido de dichas operaciones, si bien las primeras se hicieron en el entorno del monasterio, no parece que fueran con la intención de ampliarlo, pues las dimensiones de la casa palacio del infante don Fadrique sería más que suficientes para la comunidad inicial, aparte de que en la descripción de una de estas compras una casa y solar que lindaba por dos partes con sus huertas-, se dice en el Libro Becerro que en ella se construyeron varias casas. Tampoco se compraron para ampliar casas colindantes, pues solo en un caso lindaba con otra del monasterio. En consecuencia, la estrategia fue la de ir situando las adquisiciones, o al menos una parte de ellas, en las zonas más rentables de la ciudad, de ahí que un tercio se encontrasen en las collaciones de la Catedral y del Salvador, las dos más importantes en términos económicos y, como también era frecuente en estas instituciones, otro tercio en el entorno del monasterio, en las de San Lorenzo y Omnium Sanctorum. Hay que destacar, una vez más, la tipología de las adquisiciones, las cuales tienen que ver con sus localizaciones en esas collaciones importantes, pues adquirieron dos almacenes de aceite, dos mesones, unas casas tienda y una tabla de carnicería; el resto, fueron casas.

Por lo que respecta a los vendedores, de los 24 , once fueron mujeres, de ellas, seis viudas. Dos eran esposas de miembros de la aristocracia, otras dos de artesanos, una de un ballestero y otra la mujer del mayordomo de doña Teresa González. Entre los vendedores masculinos figuraban un alcalde mayor (Juan Cerón), un veinticuatro (Luis de Medina), el pregonero mayor del concejo, un cabritero, un labrador, un mercader y un carpintero.

Aunque a gran distancia de los dos precedentes por el número de inmuebles, en otros dos monasterios femeninos las compras fueron significativas en comparación con los otros procedimientos, me refiero a los de San Leandro y Santa Paula.

El de San Leandro es un caso singular entre los conventos sevillanos medievales. Como los precedentes, fue fundado a fines del siglo xIII y contó con la protección regia; sin embargo, su patrimonio no pudo ser más modesto en estos siglos, según el Libro de Protocolos, pues únicamente figuran doce inmuebles urbanos y cinco fincas rústicas. De aquellos, solo dos fueron donación de sendas religiosas. De los restantes, las monjas compraron cuatro y, mediante un 
intercambio por una finca en el Aljarafe, incorporaron una casa con cuatro tiendas. ${ }^{42}$

En este monasterio se integró, a comienzos del siglo XVI, el emparedamiento de San Pedro, por lo que en el Libro de Protocolos se recoge su patrimonio, en el que vuelve a aparecer la importancia de las compras. De las ocho propiedades referenciadas, siete fueron compras. Un dato que destacar es la concentración de dichas adquisiciones en solo dos años, 1490 y 1491, y supusieron un desembolso de 150.000 mrs. $^{43}$, lo que reflejaría la posición social de las mujeres que lo integraban o, al menos, de algunas de ellas. Tres de las casas compradas estaban situadas en la calle de la Feria, propiedad de Catalina Rodríguez Grajeda. Otro vendedor fue el caballero Gonzalo Gómez de Cervantes.

En la misma línea se encuentra el monasterio de Santa Paula, de la orden jerónima, fundado en 1475, por doña Ana de Santillán. La fundadora aportó 10 inmuebles urbanos, en uno de los cuales se estableció el monasterio. En lo que resta de centuria se incorporaron otros doce. De los que cuatro lo fueron por la fundadora y dos donaciones de sendas monjas al ingresar, el resto (6) fueron compras efectuadas en distintas collaciones, una de las cuales fue una casa horno de bizcocho. ${ }^{44}$ Esta política de compras se mantuvo en la siguiente centuria. ${ }^{45}$

El tercer grupo de instituciones eclesiásticas es el de las cofradías hospitales. Se trataba de instituciones de origen popular en la generalidad de los casos con finalidades diversas, pero que se pueden sintetizar en dos: el culto y la labor asistencial. Actividades que se podían compartir o darse de forma exclusiva. Si bien el término hospital se empleó en los siglos medievales y modernos para designar la sede de la cofradía, en los casos en que desarrollaron también una labor

42 Cf. Archivo Monasterio de San Leandro (ACSL), Libro de Protocolos. Cf. MiURA, Frailes, 145; Salvador Guijo PéREz, "Relación y formación del patrimonio urbano del monasterio de San Leandro de Sevilla. Siglos XIII-XVI", Estudios sobre patrimonio, cultura y ciencias medievales, 19/2 (2017) 809-834; Salvador Guijo Pérez, “El patrimonio rural y los censos del monasterio de San Leandro de Sevilla. Siglos XIII-XVI", Estudios sobre patrimonio, cultura y ciencias medievales, 20 (2018) 283-308.

43 Cf. ACSL, Libro de protocolos, ff. 33, 37, 69, 109, 125, 312.

44 Cf. Archivo Monasterio de Santa Paula (ACSP), Cuaderno de la fundación y Libro de Protocolos.

45 Cf. López Martínez, La economía, 199-206. 
asistencial, lo normal es que tuviese lugar en ellos. ${ }^{46}$ Estas instituciones fueron muy numerosas en los siglos medievales, hasta el punto de que podrían acercarse al centenar. ${ }^{47}$

Aunque constituyeron la excepción, lo dicho no excluye que algunos hospitales naciesen sin vinculación alguna con cofradía, e incluso que se debiesen a iniciativas individuales y con una exclusiva y concreta labor asistencial. Tal fue el caso del de Santa Marta, fundado por el arcediano Fernán Martínez de Écija; el de San Hermenegildo, por el cardenal Juan de Cervantes; la Casa de Jerusalén, por el teniente del alcalde mayor, el bachiller Bartolomé Martínez de Herrera, y el de la Sangre o de las Cinco Llagas, por doña Catalina de Ribera, viuda del Adelantado de Andalucía, don Pedro Enríquez.

Desde el punto de vista sociológico, los que sostuvieron estas actividades cultuales y/o asistenciales fueron personas procedentes de los grupos populares de la sociedad sevillana —artesanos, sector servicios, profesionales o funcionarios- Podían abarcar una gama amplia de ayudas: alojamiento, alimentación, indumentaria, dotes para jóvenes solteras, etc. A su vez, la atención podía circunscribirse a los miembros de la corporación religiosa o profesional, o abrirse a cualquier persona necesitada. De todas formas, considerada individualmente la actividad asistencial de cada cofradía-hospital, esta fue bastante modesta, como ponen de manifiesto los datos sobre el número de camas declarados por algunas, que normalmente estaba por debajo de la decena, en los casos en que se trataba de instituciones dedicadas a la acogida. ${ }^{48}$

Esta modestia de la labor asistencial estaba relacionada con la mencionada extracción social, con el número de los cofrades que integraban cada corporación y con su capacidad para generar recursos económicos —básicamente, limosnas y rentas inmobiliarias-. Esto último constituyó el talón de Aquiles de muchas, hasta el punto de

46 Cf. Juan Ignacio Carmona García, "Cofradías y asistencia en el Quinientos. Una valoración crítica", en León Carlos Álvarez SANTALÓ (coord..), Estudios de Historia Moderna en homenaje al profesor Antonio García-Baquero, Sevilla, Universidad de Sevilla, 2009, 274-286.

47 Cf. Matilde Hermoso Mellado-Damas, "Las advocaciones de los hospitales sevillanos en la Baja Edad Media", en Las ciudades andaluzas (siglos XIII-XVI). Actas del vI Coloquio Internacional de Historia Medieval de Andalucía, Málaga, Universidad de Málaga, 1991, 265-275. Cf. Pérez GonZÁlez, Los laicos, 198-274.

48 Cf. Juan Ignacio CARmona García, El sistema de la hospitalidad pública en la Sevilla del Antiguo Régimen, Sevilla, Diputación Provincial, 1979, 104. 
que la pluralidad de advocaciones con que bastantes hospitales fueron conocidos reflejarían un proceso de concentración, motivado por la falta de recursos. El resultado final, después de varios intentos, fue la fusión promovida por la administración central, en virtud de la cual, la mayor parte de los hospitales se fundieron en dos, en 1587.

Esta realidad es la que refleja la documentación utilizada. Salvo casos concretos, sus propiedades fueron escasas. La mayoría, en el supuesto de que tuviesen inmuebles, estarían por debajo de la decena. ${ }^{49}$ Constituyen la excepción los hospitales con algún tipo de vinculación o respaldo institucional: el Hospital de la Misericordia Vieja, en el Salvador, creado por un colectivo de médicos y cirujanos a raíz de la epidemia de 1384, pero que ofrecieron su patronazgo al cabildo municipal, contaba con 33 en 1452; el Hospital de Santa Marta, fundado por el arcediano de Écija Fernán Martínez de Écija y administrado por el Cabildo Catedral, contaba con 24 en 1489; el Hospital de San Hermenegildo, cuyos patronos fueron un miembro del Cabildo Catedral y los priores de la Cartuja y del monasterio de San Jerónimo, poseía 87 a fines del siglo XV, constituyéndose en el mayor propietario..$^{50}$ Otros sin este tipo de vinculaciones también consiguieron reunir un cierto número de inmuebles, como el Hospital de los Desamparados (26) o el de la Misericordia Nueva (24) ${ }^{51}$.

Aunque el mecanismo dominante de formación de sus patrimonios fue la donación, las compras tuvieron cierto protagonismo en algunos, como en el del Cardenal, que las concentró en veinte años (1473-1493), y por cuya vía obtuvieron la cuarta parte de los

49 Los fondos de estos hospitales se encuentran en el Archivo de la Diputación Provincial. Se ha perdido una gran parte de la documentación medieval, por lo que el único dato que permite tener una visión de conjunto es de finales del siglo XVI, cuando se llevó a cabo la remodelación del sistema hospitalario, que implicó la desaparición de la mayoría. Según la información de ese momento, la media de propiedades de los 73 hospitales afectados era de 9'5 (cf. CARMONA García, El sistema de la hospitalidad, 479-481).

50 Cf. Archivo Municipal de Sevilla, Sección 16, n 310. ACS, Hospital de Santa Marta, libro 39. Archivo de la Diputación Provincial de Sevilla (ADPS), Hospital del Cardenal, Libro de Protocolos, leg. 15. El Hospital de S. Hermenegildo fue más conocido por el del Cardenal, al haber sido fundado por el cardenal Juan de Cervantes.

51 Cf. ADPS, Hospital del Espíritu Santo, Libro Protocolo, 2B; Archivo Histórico Provincial de Sevilla (AHPS), Hospital de la Misericordia, Libro de protocolo, 4.735 . 
inmuebles (25,3\%). En otros de menor entidad, como en el de los Ángeles, también presentan un porcentaje significativo. Como se puede ver en la entrada "Otros hospitales" (cuadro 2), en la que he agrupado toda la información que he podido obtener relativa a las propiedades de 36 con escasas propiedades, las compras supusieron un $20 \%,{ }^{52}$ desde mediados del siglo XIV hasta 1500 , y en alguno, como en el de la Candelaria y Santa Ana superaron a las donaciones registradas.

En cuanto a las donaciones, el del Cardenal, aun manteniendo algún rasgo común, se diferencia claramente del resto por la procedencia social de los donantes. El rasgo común es el que las mujeres constituyen el grupo mayoritario (23), entre las que figuran dos beatas, y cuatro artesanas o mujeres de artesanos. El otro grupo mayoritario es el de los eclesiásticos (20), de los cuales ocho eran miembros del Cabildo Catedral, al que, como he indicado, estaba ligado el hospital, entre los que se incluyen tres de sus administradores. Los restantes donantes tenían diferentes procedencias: dos eran miembros de la aristocracia (Per Afán de Ribera y la mujer de un jurado), un criado del conde don Juan de Guzmán, un bachiller, dos artesanos del libro y un cargador del muelle. ${ }^{53}$ También destacan donaciones de cierta relevancia, como la de Inés de Herrera, que entregó cuatro casas; además, dos racioneros, un canónigo, otro clérigo y un bachiller donaron tres casas cada uno.

Los hospitales de los Desamparados y el de la Misericordia Nueva, todavía están próximos al del Cardenal, pues los clérigos siguen siendo numerosos, a su escala, incluso algunos pertenecían al alto clero y a la jerarquía (un obispo de Cádiz), al igual que se encuentran miembros de la aristocracia, como el Adelantado de Andalucía, don Pedro Enríquez, y un provincial de la Santa Hermandad; otra de las donantes fue la viuda de Juan Normán, maestro mayor de la Catedral. Pero, en cualquier caso, se trata de excepciones.

Esto lo corroboran las cifras de "Otros hospitales". Entre los 99 donantes, solo aparecen cinco clérigos, un veinticuatro, un teniente

52 Cf. ADPS, Hospital de San Lázaro, Libro de Protocolos, leg. 8; Hospital de San Eloy, Libro de Posesiones, ${ }^{\circ} 31$ (sig. antigua); Hospital de los Inocentes, Libro de Protocolos, leg. 14; Hospital del Espíritu Santo, Libro Protocolo 2B; Hospital del Amor de Dios, Sec. $1^{a}$, carps. 5, 10, 20, 22, 25, 27, 33, 34, 35 (sig. antigua). (AHPS) Hospital de la Misericordia, Libro protocolo, 4.735.

53 Cf. ADPS, Hospital del Cardenal, Libro de Protocolos, leg. 15. 
de alcalde mayor, en tanto que fundador de la Casa de Jerusalén para enfermos convalecientes, que no podían estar en hospitales, y los Reyes Católicos, que donaron al de la Sangre de Cristo la casa de un hereje que ya pagaba un censo al hospital. El resto pertenece a los tres sectores económicos — se mencionan 22 oficios diferentes-, o a sus mujeres y viudas. Respecto a las mujeres, siguieron siendo muy numerosas (45), a pesar de que no aparecen en las relaciones de cofrades, y en varios hospitales superaron a los varones donantes, como en los de San Lázaro, Ntra. Sra. de los Ángeles o San Pedro Mártir.

Tras este recorrido por el comportamiento de cada una de las instituciones, se impone un análisis de carácter temático. Como se puede observar en el cuadro 1 y se ha venido reflejando en la bibliografía, las donaciones constituyeron la vía predominante en la formación de los patrimonios inmobiliarios eclesiásticos, con el $74,5 \%$ de las operaciones. Ahora bien, este porcentaje, como todo dato global, enmascara notables diferencias. Si los datos se agrupan por tipos de instituciones, mientras que en la Catedral y en los hospitales tienen una presencia casi absoluta, con el 90,9 y 82,1 , respectivamente, en las órdenes religiosas femeninas se redujeron al 36,5\%, ya que en ellas desempeñaron un papel más destacado otras fórmulas: las herencias y las compras. A su vez, estas fórmulas también tuvieron una incidencia desigual. En San Clemente y Sta. Clara predominaron las herencias, y en esta última, además, las compras, que superaron el $20 \%$. Pero donde este procedimiento alcanzó real importancia, a pesar del escaso número de propiedades que acumularon, fue en las comunidades femeninas de San Leandro, Sta. Paula y las emparedadas de San Pedro, teniendo en cuenta que por lo que respecta a Sta. Paula no contabilizo las donaciones fundacionales. En cuanto al sentido de las citadas operaciones de compra, en todos los conventos se podría hablar de la existencia de estrategias, porque recurrieron a dicho procedimiento prácticamente desde sus orígenes, sobre todo en los más importantes; porque una parte notable de ellas se efectuaron en las collaciones centrales, de mayor nivel económico; y porque los mismos procedimientos emplearon en la formación de sus patrimonios rurales. ${ }^{54}$

54 Cf. Collantes de Terán, “Génesis”, 133-140. 
Cuadro 1. Fórmulas de adquisición de los inmuebles (1250-1500)

\begin{tabular}{|c|c|c|c|c|c|c|}
\hline INSTITUCIÓN & DONACIONES & HERENCIAS & COMPRAS & OTROS & $\begin{array}{c}\text { SIN } \\
\text { DATOS }\end{array}$ & TOTAL \\
\hline Catedral & 426 & & 7 & 1 & 43 & 477 \\
\hline $\begin{array}{l}\text { Colegiata del Salvador, } \\
\text { Cabildo }\end{array}$ & 38 & & 7 & 6 & 22 & 73 \\
\hline $\begin{array}{l}\text { Convento de } \\
\text { S. Francisco }\end{array}$ & 26 & & & & & 26 \\
\hline $\begin{array}{l}\text { Cartuja de Sta. } M^{a} \text { de las } \\
\text { Cuevas }\end{array}$ & 44 & 1 & 2 & 1 & & 48 \\
\hline $\begin{array}{l}\text { Monasterio de } \\
\text { S. Clemente* }\end{array}$ & 21 & 51 & 10 & 2 & 21 & 105 \\
\hline Monasterio de Sta. Clara & 18 & 34 & 24 & 7 & 29 & 112 \\
\hline Monasterio de Sta. Paula & 16 & & 6 & & & 22 \\
\hline $\begin{array}{l}\text { Monasterio de } \\
\text { S. Leandro }\end{array}$ & 2 & & 4 & 5 & 1 & 12 \\
\hline $\begin{array}{l}\text { Emparedadas de } \\
\text { S. Pedro }\end{array}$ & 1 & & 8 & & & 9 \\
\hline Hospital del Cardenal & 65 & & 22 & & & 87 \\
\hline Hospital de S. Eloy & 12 & & 4 & 1 & & 17 \\
\hline $\begin{array}{l}\text { Hospital de los } \\
\text { Desamparados }\end{array}$ & 26 & & & & & 26 \\
\hline $\begin{array}{l}\text { Hospital de la } \\
\text { Misericordia Nueva }\end{array}$ & 23 & & 1 & & & 24 \\
\hline Otros hospitales (36) & 110 & & 22 & & 1 & 133 \\
\hline Total & 828 & 86 & 117 & 23 & 117 & 1.171 \\
\hline
\end{tabular}

${ }^{*}$ Hay que sumar las de los compases

Por lo que respecta a los hospitales, aunque las donaciones son dominantes, hay casos concretos en los que también las compras ocuparon un papel destacado y con clara intencionalidad económica, como se pone de manifiesto en el del Cardenal. En él destaca sobre todas las operaciones la compra de seis tiendas y casas tiendas y de una taberna en las dos collaciones centrales, las de la Catedral y del Salvador, y dos de ellas, ubicadas en la Ropavieja, que lindaban con otras tantas de las que ya era propietario. Las restantes son casas, algunas de las cuales se localizaban en collaciones próximas al hospital. Para el resto de los hospitales es complicado interpretar el sentido 
de dichas operaciones. Solo en tres casos el inmueble adquirido lindaba con el propio edificio, por lo que se podría entender como una operación para ampliarlo; otros tres estaban en la misma collación del comprador, los restantes de los que hay información (13) se reparten por toda la ciudad, y de once no hay información. Sí es de destacar en estos casos que el mayor porcentaje de compras correspondió a collaciones periféricas y de la mitad septentrional de la ciudad, por tanto, en las más populares y alejadas del centro económico.

En cuanto a los donantes, la inmensa mayoría solo entregó un inmueble, pues la media se sitúa en $1,3,55$ únicamente en la Colegiata del Salvador se alcanzó el 2,2, gracias a tres donaciones que sumaron 21 inmuebles. Frente a estas modestas medias, hubo 67 personas $(12,5 \%)$ que donaron tres o más inmuebles. La presencia de estos donantes de mayor relevancia es desigual. El número más alto correspondió a la Catedral, con 44 que suponían el 21,7 \% de los donantes al Cabildo, mientras que en las órdenes religiosas masculinas fueron $19 \%$ y en las femeninas el 16,1 \%. Por su parte, en los hospitales solo aparecen siete, todos ellos menos uno en el del Cardenal. En el resto, ningún donante superó los dos inmuebles, lo que es un indicativo más del nivel social de las personas que los mantenían.

Otro tanto ocurre si se tiene en cuenta el volumen de dichas donaciones. La más importante benefició a la Colegiata del Salvador, que supuso la entrega de diez inmuebles (Arnao Tolosán). En la Catedral se documentan dos casos con ocho inmuebles, un racionero (Pedro Martínez de la Caridad) y una mujer (Guiomar Manuel); otros tantos donaron siete cada uno; uno, seis casas y 11, cinco casas; en el mínimo establecido en este sondeo, que son tres casas, figuran 20 donantes. En el grupo de las órdenes religiosas el máximo fueron seis casas, que entregaron tres personas, y otras dos que entregaron cinco. En fin, en los hospitales el máximo fueron cuatro casas, que donaron tres benefactores, y otros cinco donaron tres, como acabo de indicar, casi todos al del Cardenal.

55 En este cómputo no he tenido en cuenta la donación de los 55 inmuebles a la Catedral y al arzobispo por parte de Alfonso x. 
Cuadro 2. Distribución de los donantes por sexos

\begin{tabular}{|l|c|c|}
\hline \multicolumn{1}{|c|}{ INSTITUCIÓN } & Hombres & Mujeres \\
\hline Catedral & 165 & 39 \\
\hline Colegiata del Salvador, Cabildo & 7 & 10 \\
\hline Convento S. Francisco & 6 & 10 \\
\hline Cartuja Sta. M ${ }^{a}$ de las Cuevas & 14 & 11 \\
\hline Monasterio S. Clemente & 7 & 4 \\
\hline Monasterio Sta. Clara & 3 & 11 \\
\hline Monasterio Sta. Paula & 1 & 2 \\
\hline Monasterio S. Leandro & & 2 \\
\hline Emparedadas S. Pedro & 1 & \\
\hline Hospital Cardenal & 22 & 23 \\
\hline Hospital S. Eloy & 4 & 7 \\
\hline Hospital los Desamparados & 9 & 13 \\
\hline Hospital Misericordia Nueva & 9 & 11 \\
\hline Otros hospitales (36) & 54 & 45 \\
\hline Total & 302 & 188 \\
\hline
\end{tabular}

Respecto a la cualidad y condición de los donantes, lo primero a destacar es el considerable protagonismo de la mujer. ${ }^{56}$ Según los datos del cuadro 2, representaron el 39,4\%. Pero esta cifra creo que no refleja la realidad, ya que, una vez más, está distorsionada por la fuerte presencia de la Catedral. No tanto por el número de donantes, como por su cualidad, dada la gran presencia de miembros de la institución algo que no se dio en las restantes aquí estudiadas. Si se excluye del cómputo general a los clérigos de la Catedral, hombres y mujeres están prácticamente equilibrados, con un total de 181 y 178 donantes, respectivamente. Por instituciones, dicho equilibrio se rompe en la Catedral, donde los hombres laicos superan a las mujeres (51 y 39), y en las órdenes religiosas femeninas, en las que se invierte la relación, 19 mujeres por 12 hombres. También hay que resaltar el número de viudas (57), aunque lo más probable es que el dato no

56 Cf. Silvia Ma Pérez González, La mujer en la Sevilla de finales de la Edad Media: solteras, casadas y vírgenes consagradas, Sevilla, Ateneo - Universidad de Sevilla, 2005. 
sea real por defecto, debido a la ambigüedad con que en ocasiones se menciona a las mujeres respecto de sus maridos, en el sentido de que no queda claro si estos han fallecido o no (cuadro 3). Aparte de su condición de viuda, en el caso de que lo sean, es frecuente que de las mujeres no se ofrezca otra información. Con todo, de algo menos de la mitad hay referencias a sus actividades o su ubicación en la sociedad: 24 eran religiosas ( 6 beatas, freilas y emparedadas; 18 monjas), 17 pertenecían a la nobleza y a la aristocracia, 12 eran artesanas o mujeres de artesanos; 7 mujeres de oficiales públicos; seis estaban vinculadas —ellas o sus maridos- al sector servicios; además, una era esposa de mercader, otras domésticas y familiares de arzobispos o clérigos de la Catedral.

El siguiente grupo por el volumen de donantes es el de los clérigos, debido al ya mencionado protagonismo en las donaciones catedralicias (cuadro 3). De ahí que, si se excluye a estos, su presencia en el resto de las instituciones desciende considerablemente. Solo fueron significativos en el monasterio de Sta. Clara y en el Hospital del Cardenal, en este caso, por su vinculación con la Catedral, pues aparecen siete canónigos y racioneros, de los que algunos fueron sus administradores. ${ }^{57}$ Por otro lado, llama la atención la casi nula presencia de clérigos donantes en la Colegiata del Salvador, aunque, como ya he apuntado, es posible que se encuentren entre los que no dan ninguna información sobre sus profesiones.

Por lo que se refiere a los laicos hay una nítida diferencia entre las élites y los grupos populares pertenecientes a los tres sectores económicos. La nobleza y los altos cargos de la administración regia se vincularon a la Catedral y solo excepcionalmente aparecen donando a algún convento u hospital. A su vez, el segundo escalón, el de caballeros hidalgos y ciudadanos, repartieron sus vinculaciones entre la Catedral, la Colegiata del Salvador y los conventos, especialmente con los masculinos, y en menor medida con los hospitales. Frente a esta presencia más o menos dominante de clérigos, nobles, caballeros y altos cargos, en las instituciones mencionadas, los hospitales fueron mantenidos prioritariamente por los sectores populares, que son los que conformaron las cofradías y los colectivos que se aglutinaron en torno a hospitales. Me refiero a artesanos, oficios

57 Cf. Antonio Manuel González Díaz, Poder urbano y asistencia social: el Hospital de San Hermenegildo de Sevilla (1453-1837), Sevilla, Diputación Provincial, 1997. 
públicos de nivel medio y pertenecientes al sector servicios, así como sus mujeres, pero teniendo en cuenta que se trataba de personas con un cierto nivel económico, porque poseían casas o algún que otro inmueble que eran el objeto de sus donaciones.

Hay un último aspecto de esta propiedad inmobiliaria eclesiástica sobre el que conviene llamar la atención: el del elevado número de inmuebles destinados a actividades económicas que formaron parte de sus patrimonios, muchos llegados vía donaciones. Si bien, como era lógico, la casa fue el bien donado por excelencia, esos otros edificios superaron la cifra de 300: alhóndigas, almacenes, atahonas, baños, bodegas, hornos, huertas, lagares, mesones, tablas de carnicería, tiendas, tenerías, tabernas, etc.

En su distribución entre las distintas instituciones, de nuevo, la Catedral se impuso a los conventos y hospitales, tanto en valores absolutos como relativos. Los 196 inmuebles de esta tipología supusieron el 40,5\% del total de los donados, mientras que los 150 de conventos y hospitales, representaron el 22,8 \% de los entregados a estos dos tipos de instituciones. El Cabildo Catedral acumuló, al menos, 20 almacenes o casas almacenes y alhóndigas; 16 bodegas o casas bodegas; otros tantos mesones o casas mesones; y 8 hornos de pan o casas hornos. Por su parte, los conventos llegaron a reunir, entre otros inmuebles, 14 hornos, 11 almacenes y alhóndigas o 9 tablas de carnicería. En este caso, no todos fueron donaciones, sino que también se incluyen herencias y compras.

Con ser significativo el número de estos edificios, la cifra más alta y con diferencia correspondió a las tiendas y casas tiendas. La Catedral fue propietaria de 117 según el Libro Blanco, ${ }^{58}$ mientras que los conventos lo fueron de 70 y los hospitales de 10. Aparte de estas diferencias en valores absolutos, también se dieron en los relativos. Las tiendas de la Catedral supusieron el 40,5\% de sus inmuebles, mientras que en los conventos y hospitales bajaron al 22,8 \%.

Como he indicado, los reyes apenas entregaron inmuebles a estas instituciones, pero, con excepción de Alfonso x, en todos los casos en que lo hicieron se trató de tiendas. ${ }^{59}$ Este monarca, aparte de otras,

58 Hay que recordar que en el Libro Blanco solo figuraban los bienes donados para dotar sepulturas y sufragios, por lo que el número sería mayor. De hecho, en él no consta la donación por parte de Alfonso xI de diez tiendas en los Alatares.

59 Tras la conquista de la ciudad, el rey se reservó la propiedad de las tiendas, de las que tanto Fernando III como sus sucesores se fueron desprendiendo en beneficio 
donó a la Catedral las que se encontraban en su entorno y Alfonso XI, diez en los Alatares, junto al Salvador. Por su parte, Fernando IV, entregó cinco tiendas de la Ollería al monasterio de San Clemente. ${ }^{60}$ También se podría hablar de donaciones regias indirectas, pues, aunque fueron concedidas a particulares, acabaron entrando en el patrimonio de alguna de estas instituciones probablemente en el plazo de una generación, como ocurrió en S. Clemente. Me refiero a las doce tiendas de los Alatares entregadas por Alfonso XI a doña Marina Gómez de Sotomayor, monja en las Huelgas de Burgos, que heredó su hija doña María Rodríguez de Rojas, monja en S. Clemente, y que luego heredó el monasterio ${ }^{61}$. Además, hay dos lotes de tiendas, que bien podrían ser otras tantas donaciones regias. Uno de ellos lo integran las doce que estaban junto a los baños de don Fadrique, en la collación de San Vicente, las cuales figuran en la relación de mezquitas y otros edificios de la Catedral incluida en el Libro Blanco, por tanto, es anterior a 1411. El otro lote son siete tiendas en la Ollería, propiedad del monasterio de Sta. Clara, del que no hay más información, salvo su arriendo como un todo ${ }^{62}$.

Aparte de estas donaciones regias, hasta 59 personas (17 de ellas mujeres) entregaron tiendas o casas tiendas a las distintas instituciones. Algunas fueron importantes. En este sentido, de nuevo la Catedral es la que resultó más favorecida con el mayor número y las más cuantiosas. Nicolás Pérez de Villafranca, escribano mayor del concejo, donó siete en la Ollería. Doña Guiomar Manuel, seis en la Alcaicería. El canónigo Alfonso Segura, cinco también en la Alcaicería. Siete personas más fueron donantes de cuatro tiendas: un arzobispo, cuatro canónigos, otro clérigo y la viuda del alcalde mayor Fernán Martínez. Estas cifras ponen una vez más de relieve la riqueza y posición social de los beneficiarios de la Catedral, pues frente

de particulares y de distintas instituciones (cf. José Damián GonZÁLEZ ArCE, "Las rentas del almojarifazgo de Sevilla", Studia Historica, Historia Medieval 15 [1997] 211-214).

60 Cf. Julio GonzÁLEz, El repartimiento de Sevilla, Sevilla, CSIC, 1951, II, 324. Isabel Montes ROMERO-CAMACHO, "La documentación de Alfonso XI conservada en el archivo de la Catedral de Sevilla", en Estudios en memoria del profesor don Salvador de Moxó, Madrid, Universidad Complutense, 1982, II, 139. Borrero Fernández, El Archivo del Real Monasterio de San Clemente, Sevilla, Ayuntamiento de Sevilla, $1992, \mathrm{n}^{\circ} 120$.

61 Cf. Borrero Fernández, El Archivo, no 144.

62 Cf. Belmonte, Organizar, 505. AMSMJS, LBSC, f. 76. 
a ellos los donantes de los conventos y hospitales fueron menos (16), así como el volumen de sus donaciones. Solo un orfebre, Diego Martínez, llegó a entregar tres tiendas en la Alcaicería a la Cartuja de las Cuevas. También excepcional, como ya he indicado, fue la acumulación de que se benefició la Colegiata del Salvador.

Las herencias y las compras contribuyeron menos a las adquisiciones de tiendas, aunque fueron significativas por su localización. Las herencias se reducen al monasterio de San Clemente, que aparte de las doce ya mencionadas de doña María Rodríguez de Rojas, también heredó cuatro de Elvira Sánchez en la calle de Francos, una de Sancha González Barba y otra de Leonor Rodríguez Barba; y en menor medida al de Sta. Clara, con solo dos. En cuanto a las compras, curiosamente el monasterio de Sta. Clara, que se caracterizó por su política de compras, no consta que invirtiese en tiendas, mientras que sí fue interesante para el Hospital del Cardenal, que adquirió seis. Los datos de la Catedral tienen que ser imprecisos. Según el Libro Blanco se adquirieron siete en distintos puntos de la ciudad con dinero procedente de mandas, y en 1297 siete en Sta. Catalina, igualmente con el importe de varias mandas en metálico. ${ }^{63}$

Este impresionante trasvase de edificios de carácter económico protagonizado fundamentalmente por miembros de los estamentos más altos de la sociedad sevillana, tanto laicos como eclesiásticos, pone de manifiesto el interés que mostraron, desde el primer momento, por acceder a su propiedad. Para los reyes, propietarios iniciales de tan importante patrimonio inmobiliario como consecuencia de la conquista, fue un medio de recompensar servicios prestados o de atraer voluntades.

Cualquiera que fuese la importancia de las adquisiciones y su fórmula, en lo que coincidieron todas las instituciones es en la ubicación de las tiendas en los dos centros económicos de Sevilla: en los entornos de la Catedral y de la Colegiata del Salvador, que se habían configurado como tales centros comerciales ya en la etapa andalusí (plano). ${ }^{64}$

63 Cf. GonzÁLez, El repartimiento, II, 368.

64 Agradezco a Francisco Pinto la confección de este plano. 
Áreas de centralidad urbana de Sevilla

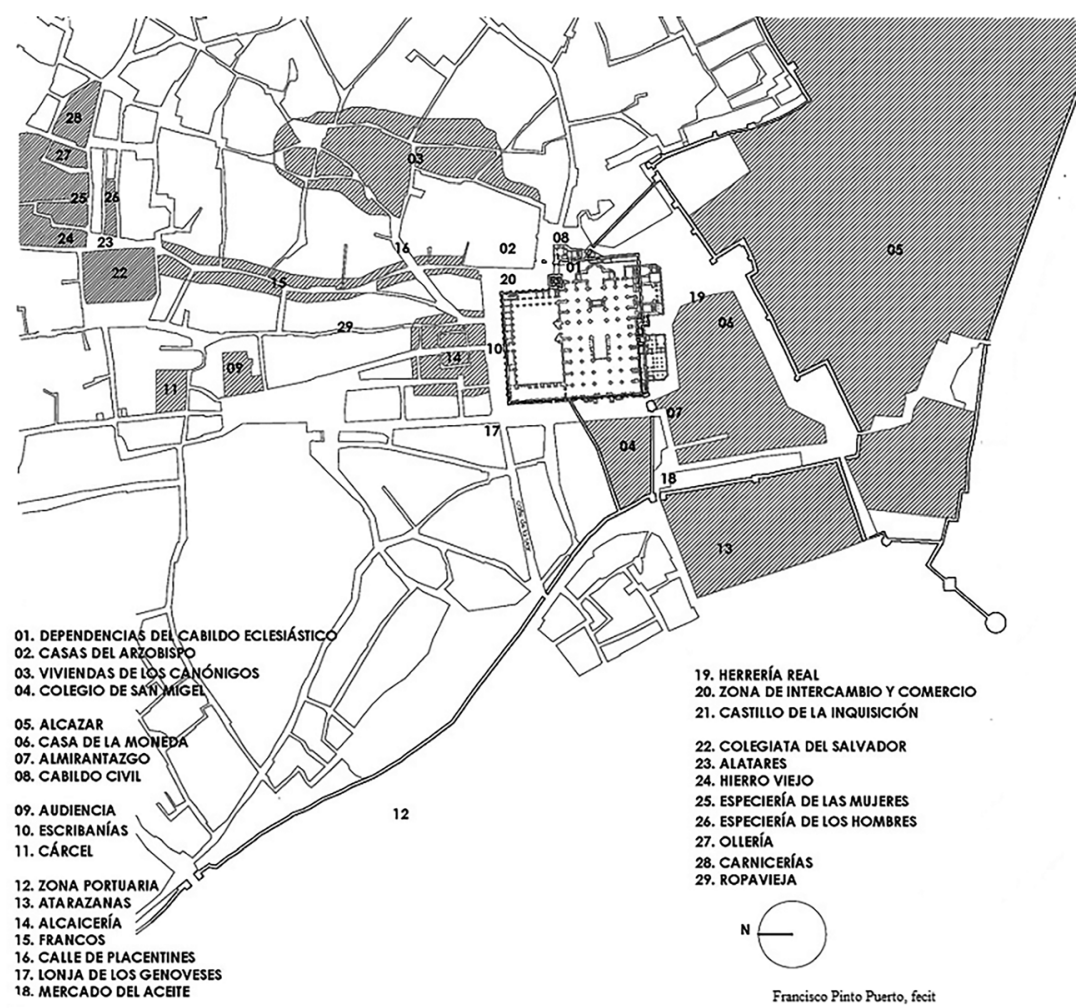

En la vecindad de la Catedral se encontraba la Alcaicería, aunque sería mejor decir las Alcaicerías, pues en ocasiones se mencionan sectores especializados: de los paños, de los alfayates, de los plateros, de los traperos, etc. Aquí poseía el Cabildo Catedral 14, cinco de ellas donadas por el canónigo Alfonso Segura, y la Fábrica seis; otras tantas en la de los Traperos; también el monasterio de Sta. Clara (6) y la Cartuja de las Cuevas (4). Además, se podría decir que las calles de su entorno estaban conformadas por una sucesión de tiendas, muchas de las cuales pertenecieron a estas instituciones, encabezadas por la propia Catedral que llegó a poseer en este espacio 63 de las 91 que registra el Libro Blanco. En la calle de las Gradas, que bordeaba la Catedral, tuvieron tiendas la Catedral (7) y el Hospital del Cardenal 
(2), y en la inmediata plazuela de Sta. María otras siete el Cabildo Catedral.

La collación del Salvador fue otro espacio comercial, en el que se han documentado 53 tiendas de instituciones eclesiásticas a fines del siglo XV. Especialmente denso en este sentido fue el propio entorno de la colegiata y el espacio entre esta y la actual Alfalfa, donde se localizaba la Alcaicería más antigua. Es la que los documentos medievales denominan también Alatares y posteriormente fue conocida por Especiería de los Hombres (actual Herbolarios) y Especiería de las Mujeres (actual Alcaicería de la Loza). Donde también se encontraba la Ollería, es decir, donde se concentraban las tiendas de loza y cerámica, y las tiendas o tablas de carnicería.

Casi se podría decir que fue un espacio copado por las instituciones eclesiásticas.

Según los libros de apeos de la Catedral de 1502, el Cabildo poseía en la Especiería de los Hombres 23 tiendas, la mayor parte en la acera izquierda a contar desde el Salvador; mientras que la Fábrica tenía cinco en la Especiería de las Mujeres. San Clemente heredó 11 de María Rodríguez de Rojas y el Hospital de la Misericordia del Salvador tuvo dos. La Colegiata tenía tres en la de las Mujeres y una en la de los Hombres, además de todas las que la rodeaban adosadas a sus muros, como testimonian las que hoy se conservan en la plaza de Jesús de la Pasión (o del Pan).

Por su parte, en la Ollería recibió el Cabildo Catedral siete de Nicolás Pérez de Villafranca, cinco el monasterio de San Clemente de Fernando Iv y siete eran propiedad del de Sta. Clara. En fin, en las Carnicerías poseyeron tablas la Colegiata (9), la Cartuja de las Cuevas (7), el monasterio de Sta. Clara (3), el de San Francisco (1) y la parroquia de San Juan (3).

Sirviendo de nexo de unión entre ambos espacios comerciales se encontraban las calles Placentines-Francos y la actual Álvarez Quintero, que fueron otros tantos ejes comerciales y con presencia de tiendas de propiedad eclesiástica. En el primero, la Catedral (11), el monasterio de San Clemente (6) y la Cartuja (1). En el segundo, conocido en parte como la Ropavieja, el monasterio de San Clemente (1), el de Sta. Clara (2) y el Hospital del Cardenal (4). 
En conclusión, las instituciones eclesiásticas sevillanas acumularon un notable patrimonio inmobiliario entre los siglos XIII y XV, en el que los de la Catedral y, a cierta distancia, los de varios monasterios femeninos destacaron por su volumen. La mayor parte fueron casas, pero los edificios susceptibles de albergar actividades económicas de muy distinto signo, especialmente tiendas, constituyeron una parte importante de los citados patrimonios en algunas de ellas, con el añadido de su concentración en las áreas comerciales de las collaciones de mayor nivel económico y centralidad de la ciudad.

Las donaciones constituyeron el procedimiento más generalizado del que se nutrió esta propiedad inmobiliaria, pero en varios monasterios femeninos las herencias de sus propias monjas se impusieron a aquellas, y en otros, así como en varios hospitales, las compras fueron el factor dominante.

Los datos disponibles sobre la condición y procedencia social de los donantes reflejan una notable igualdad entre hombres y mujeres, si se excluye a la Catedral, debido al peso excepcional que en esta tuvieron los miembros de su Cabildo. Dicha igualdad se rompe a favor de las mujeres en los monasterios femeninos y en algunos hospitales. Por lo que se refiere al papel de los distintos sectores sociales, la actuación de las élites se centró en la Catedral, Colegiata del Salvador y los conventos, mientras que los grupos intermedios y populares lo hicieron en los hospitales. 


\begin{tabular}{|c|c|c|c|c|c|c|c|c|c|c|c|c|c|c|c|}
\hline 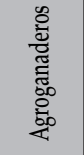 & & & & & & & & & & $r$ & & & & $\infty$ & H \\
\hline 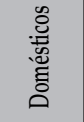 & $r$ & & & $r$ & & & & & & $r$ & & & $r$ & $r$ & in \\
\hline 总 & $N$ & & & - & & & & & & - & $\infty$ & $N$ & & $\ltimes$ & 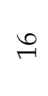 \\
\hline 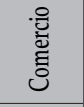 & $\infty$ & & $r$ & & & - & & & & & & & & $r$ & $\exists$ \\
\hline 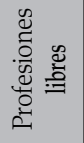 & & & & - & & & & & & $r$ & & & & & $N$ \\
\hline 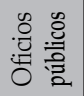 & 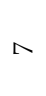 & $N$ & & & $r$ & & & & & $\infty$ & & $N$ & $r$ & $N$ & $\stackrel{\infty}{\sim}$ \\
\hline 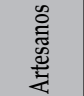 & $N$ & $\neg$ & & $\infty$ & & & & & & $H$ & & $m$ & $r$ & $\exists$ & $\stackrel{\stackrel{2}{N}}{N}$ \\
\hline 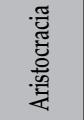 & 우 & H & 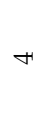 & 10 & $r$ & & $N$ & & & $N$ & & & $N$ & $r$ & $\vec{\omega}$ \\
\hline 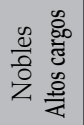 & $\stackrel{ }{\circ}$ & & $r$ & & & & & & & & & & $r$ & $r$ & $\stackrel{M}{\sim}$ \\
\hline 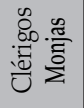 & $\stackrel{m}{\Rightarrow}$ & $N$ & & $N$ & + & 우 & & $N$ & $-r$ & 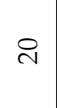 & & $\Lambda$ & 6 & in & $\stackrel{\mathbb{N}}{\sim}$ \\
\hline 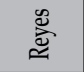 & $r$ & & & & $r$ & & & & & & & & & $r$ & $n$ \\
\hline$\overbrace{5}^{\pi}$ & $\underset{7}{ }$ & H & 10 & 0 & $r$ & $\sim$ & & & & $H$ & & H & H & ㄱ. & $\widetilde{\sigma}$ \\
\hline 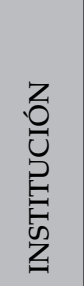 & $\begin{array}{l}\frac{\pi}{0} \\
\frac{0}{0} \\
\tilde{U}\end{array}$ & 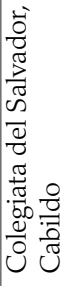 & 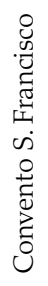 & 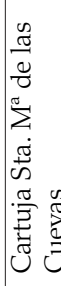 & 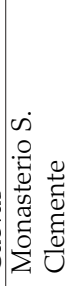 & 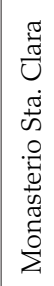 & 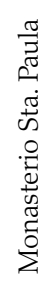 & 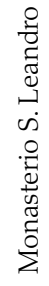 & 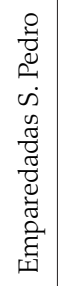 & 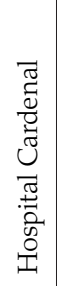 & 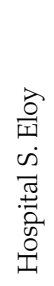 & 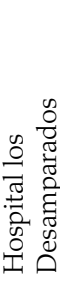 & 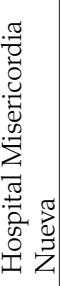 & 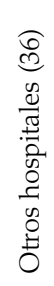 & స్ \\
\hline
\end{tabular}


